\title{
REDUCING HOSPITAL STAY IN CHILDREN WITH DIABETIC KETOACIDOSIS
}

\author{
Abhyuday Verma1 ${ }^{1}$ Deepika Verma ${ }^{2}$ \\ ${ }^{1}$ Consultant, Endocrinologist, Superspeciality Endocrinology and Woman Care Centre, Indore, Madhya Pradesh. \\ ${ }^{2}$ Consultant Gynaecologist, Superspeciality Endocrinology and Woman Care Centre, Indore, Madhya Pradesh.
}

\begin{abstract}
Diabetic ketoacidosis is a major cause of morbidity and mortality in patients with type 1 diabetes mellitus. The cost of its treatment in ICU is significant. Low-dose continuous insulin infusion is the standard regimen for correction of hyperglycemia and acidosis. We used subcutaneous insulin glargine along with intravenous regular insulin in our stable DKA patients. The results were encouraging, our patients had a smooth glycemic control and required less hospital stay. This intervention resulted in better outcome and less economic burden to our patient's family.
\end{abstract}

\section{KEYWORDS}

TIDM, DKA, Diabetic Ketoacidosis, Insulin.

HOW TO CITE THIS ARTICLE: Verma A, Verma D. Reducing hospital stay in children with diabetic ketoacidosis. J Evolution Med Dent Sci 2016;5(1):60, DOI: 10.14260/jemds/2016/14

\section{INTRODUCTION}

Diabetic ketoacidosis is a major cause of morbidity and mortality in patients with type 1 diabetes mellitus. The cost of its treatment in ICU is significant. Patients are usually kept in ICU till resolution of acidosis and change in insulin regimen from intravenous to subcutaneous injection. Low-dose continuous insulin infusion is the standard regimen for correction of hyperglycemia and acidosis. From past few years daily subcutaneous long acting insulin analogue glargine has been used along with short acting subcutaneous insulin to achieve a smooth glycemic control in type 1 diabetics. ${ }^{1}$ by providing long acting and smooth effect glargine acts like a constant infusion. This quality of the drug may help in smooth transition from intravenous to subcutaneous insulin in diabetic ketoacidosis patient, resulting in early transfer from ICU. 2,3

At our centre we hypothesized that initiation of glargine in initial stable phase of DKA along with intravenous insulin infusion would decrease the requirement of infusion and a speedy recovery. The patients were divided into 2 groups: subcutaneous insulin glargine + IV regular insulin (group 1) or only IV regular insulin (group 2). Patients with critical illness, pregnancy were excluded. All the patients admitted in ICU were managed as per our standard treatment algorithm (IV fluids/potassium supplementation along with continuous insulin infusion, antibiotics if required etc.).

A total of 20 children were admitted in ICU over 24 months from June 2013 to May 2015. The cause of DKA in most of our patients was skipping or deleting insulin dose. Most of the patients were from poor socioeconomic background. Ten children each were divided in group 1 and group 2 .

Financial or Other, Competing Interest: None.

Submission 10-12-2015, Peer Review 11-12-2015,

Acceptance 30-12-2015, Published 04-01-2016.

Corresponding Author:

Dr. Abhyuday Verma,

5/1 Pardeshipura,

Indore-452003,

Madhya Pradesh.

E-mail: abhyudaya76@yahoo.com

DOI:10.14260/jemds/2016/14
The details of patient at admission are (group1/group2): age of children (years) $11.5(+2.7) / 11.2(+2.1)$, female: male $12: 8$, initial blood glucose $450(+152) / 490(+118)$, venous $\mathrm{pH}$ : $7.14(+0.09) / 7.06(+0.11)$, serum sodium $134(+2.0) / 135$ (+1.6). As per DKA management protocol of our ICU, fluid and electrolytes management was done.

\section{RESULTS}

At the end of treatment the outcome measures were (group1/group2), total IV insulin dose (IU/day): $46(+15) / 70$ $(+22)$, insulin infusion time (hours): $24(+2.2) / 34(+1.8)$ and mean hospital stay (days): $4(+0.9) / 6 \quad(+1.5)$. Fluid requirement were similar in both groups and no hypos were seen with use of glargine. Most of our patients in glargine group had a smooth control of blood sugars with less variability.

\section{CONCLUSION}

This small cohort of patients shows that children receiving insulin glargine along with regular insulin infusion for control of hyperglycemia in DKA required less dose of insulin infusion and less glycemic variability. Therapy with glargine along with insulin infusion considerably decreased the length of ICU stay and the cost of hospitalization. This can substantially cut the financial burden of therapy, as most of them were from poor socioeconomic background.

\section{REFERENCES}

1. Mohammad HA, Farghaly HS, Metwalley KA, et al. Predictors of glycemic control in children with type 1 diabetes mellitus in Asyut-Egypt. Indian J Endocr Metab, 2012;16:796-802.

2. Elisa Hsia, Stacey Seggelke, Joanna Gibbs, et al. Subcutaneous administration of glargine to diabetic patients receiving insulin infusion prevents rebound hyperglycemia. JCEM 2012;97(9):3132-3137.

3. Shankar V, Haque A, Churchwell KB, et al. Insulin glargine supplementation during early management phase of diabetic ketoacidosis in children. Intensive Care Med, 2007;33:1173-1178. 